\title{
Retinogeniculate Synaptic Properties Controlling Spike Number and Timing in Relay Neurons
}

Dawn M. Blitz and Wade G. Regehr

J Neurophysiol 90:2438-2450, 2003. doi:10.1152/jn.00562.2003

You might find this additional info useful...

This article cites 40 articles, 24 of which can be accessed free at:

http://jn.physiology.org/content/90/4/2438.full.html\#ref-list-1

This article has been cited by 17 other HighWire hosted articles, the first 5 are:

Spike Timing and Information Transmission at Retinogeniculate Synapses

Daniel L. Rathbun, David K. Warland and W. Martin Usrey

J. Neurosci., October 13, 2010; 30 (41): 13558-13566.

[Abstract] [Full Text] [PDF]

The importance of $N$-methyl-d-aspartate (NMDA) receptors in subtraction of electrosensory reafference in the dorsal nucleus of skates

Zhi Zhang and David Bodznick

J Exp Biol, August 1, 2010; 213 (15): 2700-2709.

[Abstract] [Full Text] [PDF]

Context-Dependent Effects of NMDA Receptors on Precise Timing Information at the

Endbulb of Held in the Cochlear Nucleus

Lioudmila Pliss, Hua Yang and Matthew A. Xu-Friedman

J Neurophysiol, November , 2009; 102 (5): 2627-2637.

[Abstract] [Full Text] [PDF]

Impact of Synaptic Depression on Spike Timing at the Endbulb of Held

Hua Yang and Matthew A. Xu-Friedman

J Neurophysiol 2009; 102 (3): 1699-1710.

[Abstract] [Full Text] [PDF]

Preserving Information in Neural Transmission

Lawrence C. Sincich, Jonathan C. Horton and Tatyana O. Sharpee

J. Neurosci., May 13, 2009; 29 (19): 6207-6216.

[Abstract] [Full Text] [PDF]

Updated information and services including high resolution figures, can be found at:

http://jn.physiology.org/content/90/4/2438.full.html

Additional material and information about Journal of Neurophysiology can be found at: http://www.the-aps.org/publications/jn

This infomation is current as of July 20, 2011.

Journal of Neurophysiology publishes original articles on the function of the nervous system. It is published 12 times a year (monthly) by the American Physiological Society, 9650 Rockville Pike, Bethesda MD 20814-3991. Copyright (C) 2003 by the American Physiological Society. ISSN: 0022-3077, ESSN: 1522-1598. Visit our website at http://www.the-aps.org/. 


\title{
Retinogeniculate Synaptic Properties Controlling Spike Number and Timing
} in Relay Neurons

\author{
Dawn M. Blitz and Wade G. Regehr \\ Department of Neurobiology, Harvard Medical School, Boston, Massachusetts 02115
}

Submitted 11 June 2003; accepted in final form 10 July 2003

Blitz, Dawn M. and Wade G. Regehr. Retinogeniculate synaptic properties controlling spike number and timing in relay neurons. $J$ Neurophysiol 90: 2438-2450, 2003; 10.1152/jn.00562.2003. Retinal ganglion cells (RGC) transmit visual signals to thalamocortical relay neurons in the lateral geniculate nucleus via retinogeniculate synapses. Relay neuron spike patterns do not simply reflect those of RGCs, but the mechanisms controlling this transformation are not well understood. We therefore examined synaptic properties controlling the strength and precision of relay neuron firing in mouse (p2833) brain slices using physiological stimulation patterns and a combination of current clamp and dynamic clamp. In tonic mode (-55 $\mathrm{mV}$ ), activation of single RGC inputs elicited stereotyped responses in a given neuron. In contrast, responses in different neurons varied from unreliable, to faithfully following, to a gain in the number of spikes. Dynamic clamp experiments indicated these different responses primarily reflected variability in the amplitudes of the $N$-methyl-Daspartate (NMDA) and AMPA components. Each of these components played a distinct role in transmission. The AMPA component evoked a single precisely timed, short-latency spike per stimulus, but efficacy decreased during repetitive stimulation due to desensitization and depression. The NMDA component elicited longer-latency spikes and multiple spikes per stimulus and became more effective during repetitive stimuli that led to NMDA current summation. We found that in burst mode $(-75 \mathrm{mV})$, where low-threshold calcium spikes are activated, AMPA and NMDA components and synaptic plasticity influenced spike number, but no combination enabled relay cells to faithfully follow the stimulus. Thus the characteristics of AMPA and NMDA currents, the ratio of these currents and use-dependent plasticity interact to shape how RGC activity is conveyed to relay neurons.

\section{IN T R O D U C T I O N}

Visual signals from the retina are encoded in the activity of retinal ganglion cells (RGCs) and are transmitted to relay neurons in the lateral geniculate nucleus (LGN) of the thalamus before reaching neurons in visual cortex. Many factors are known to influence relay neuron activity, including modulatory inputs, GABAergic interneurons, cortical feedback, and intrinsic conductances of relay neurons (McCormick 1992; Sherman and Guillery 1996; Steriade et al. 1997). However, there remain many unresolved questions regarding how RGC activity is transformed into relay neuron firing. First, why do relay neuron responses not faithfully follow RGC input (Cleland and Lee 1985; Usrey 2002; Usrey et al. 1999) despite the large amplitude of RGC-elicited synaptic currents in relay neurons (Chen and Regehr 2000; Chen et al. 2002)? Second, what

Address for reprint requests and other correspondence: W. Regehr, 220 Longwood Ave., Harvard Medical School, Boston, MA (E-mail: wade_regehr@hms.harvard.edu). underlies the ability of relay neurons to have both highly precise short-latency responses and delayed responses (Mastronarde 1987; Reinagel and Reid 2002; Usrey et al. 1999)? Third, what enables a high degree of precision in visually evoked responses across trials and cells (Liu et al. 2001; Reinagel and Reid 2000, 2002)? Fourth, does use-dependent synaptic plasticity allow the timing of RGC spikes to influence their efficacy in eliciting relay neuron spikes? Finally, visual stimuli can elicit burst firing in relay neurons, which is highly effective at activating cortical neurons (Swadlow and Gusev 2001; Usrey et al. 2000). Does this burst firing require that relay neurons be in a state that is prone to bursting (burst mode) or are there other ways to generate a burst?

The properties of the retinogeniculate synapse may provide answers to these questions. Transmission at the retinogeniculate synapse is mediated by AMPA and $N$-methyl-D-aspartate (NMDA) receptors (Esguerra et al. 1992; Scharfman et al. 1990). Blockade of either receptor decreases the strength of visually evoked responses in relay neurons, supporting the importance of both components in mediating these responses (Hartveit and Heggelund 1990; Kwon et al. 1991; Sillito et al. 1990). The distinctive properties of AMPA and NMDA receptors suggest they may make different contributions to relay neuron responses. The AMPA component lasts for milliseconds and has an approximately linear voltage dependence, whereas the NMDA component lasts for many tens of milliseconds but has a voltage dependence that makes it less effective at hyperpolarized potentials. In addition, these components exhibit different short-term synaptic plasticity. Both depress, but the extent of depression and the mechanisms underlying the synaptic plasticity differ for each receptor type (Chen et al. 2002). What role this plasticity may play in determining the dependence of efficacy on interspike interval is unknown.

The mode of the relay neuron also influences the transfer of visual signals across the retinogeniculate synapse. At sufficiently negative membrane potentials, low-threshold calcium channels can elicit bursts of spikes (Crunelli et al. 1989; Jahnsen and Llinas 1984a,b). In contrast to this burst mode, at more depolarized potentials, the low-threshold calcium channels are inactivated, and relay neurons are in a tonic response mode (Sherman 2001b). Although neurons in the awake animal are more commonly in tonic mode, visual stimuli elicit both tonic and burst responses (Guido and Weyand 1995; Ramcharan et al. 2000; Weyand et al. 2001). How faithfully relay

\footnotetext{
The costs of publication of this article were defrayed in part by the payment of page charges. The article must therefore be hereby marked "advertisement", in accordance with 18 U.S.C. Section 1734 solely to indicate this fact.
} 
neuron firing follows RGC input can be quite different depending on the contributions of low-threshold calcium channels. However, it is not known how synaptic properties interact with these response modes.

We used current- and dynamic-clamp recordings from LGN relay neurons in mouse brain slices to examine how synaptic properties control the response of relay neurons to stimulation of individual retinogeniculate inputs with a physiological stimulation pattern. Inhibitory and cortical feedback were eliminated to focus on effects of the retinogeniculate synapse in isolation. We performed pharmacological manipulations of synaptic currents and dynamic-clamp injection of isolated AMPA and NMDA conductances to examine their role in both tonic and burst mode. The dynamic-clamp technique was used to systematically vary properties of artificial synaptic inputs and examine responses to these inputs isolated from the complications of additional circuitry. Dynamic-clamp experiments also enabled us to manipulate activity-dependent plasticity and examine its influence without altering other properties of the synapse, something that is not possible with real synaptic inputs. This study demonstrates that the precision and strength of relay neuron responses is highly sensitive to the balance of AMPA and NMDA currents, their distinct properties, and activity-dependent synaptic plasticity.

\section{METHODS}

\section{Slice preparation and solutions}

Pseudo-sagittal brain slices $(250 \mu \mathrm{m})$ containing the dorsal LGN were prepared from postnatal day 28-33 Black Swiss mice as described previously (Chen and Regehr 2000; Chen et al. 2002). Briefly, slices were cut in a sucrose solution consisting of (in mM) $82.7 \mathrm{NaCl}$, $23.8 \mathrm{NaHCO}_{3}, 71.2$ sucrose, 23.7 glucose, $2.4 \mathrm{KCl}, 1.4 \mathrm{NaH}_{2} \mathrm{PO}_{4}, 6.8$ $\mathrm{MgCl}_{2}$, and $0.48 \mathrm{CaCl}_{2}$. Slices were incubated in this solution at $32^{\circ} \mathrm{C}$ for 25-30 min and then transferred to a saline solution for 30-35 min at $32^{\circ} \mathrm{C}$. Saline solution consisted of (in $\mathrm{mM}$ ) $125 \mathrm{NaCl}, 26 \mathrm{NaHCO}_{3}$, $2.5 \mathrm{KCl}, 1.25 \mathrm{NaH}_{2} \mathrm{PO}_{4}, 25$ glucose, $2 \mathrm{CaCl}_{2}$, and $1 \mathrm{MgCl}_{2}$. Corticothalamic feedback was eliminated by severing the connection from cortex to the LGN with a scalpel. Slices were placed on glass coverslips coated with poly-L-lysine (Sigma, St. Louis, MO) and submerged in a recording chamber. Picrotoxin $(20 \mu \mathrm{M})$ was included in the saline in all experiments to block $\mathrm{GABA}_{\mathrm{A}}$ synaptic inputs. During experiments in which synaptic inputs were activated, the $\mathrm{GABA}_{\mathrm{B}}$ antagonist CGP55845a $(2 \mu \mathrm{M})$ was included in the saline to block metabotropic GABA influences elicited by repetitive RGC stimuli (Soltesz and Crunelli 1992). 3-((R)-2-carboxypiperazin-4-yl)-propyl-1-phosphonic acid (CPP) $(5-10 \mu \mathrm{M})$ and 2,3-dioxo-6-nitro-1,2,3,4-tetrahydrobenzo[f]quinoxaline-7-sulphonamide disodium (NBQX) (5-10 $\mu \mathrm{M})$ were used as indicated to block synaptically activated NMDA and AMPA receptors, respectively. During dynamic-clamp experiments, the only receptor antagonist included in the saline was picrotoxin. All drugs were obtained from Tocris (Ellisville, MO).

\section{Electrophysiology}

Whole cell recordings were made from relay neurons in the LGN as described previously (Chen and Regehr 2000; Chen et al. 2002). Relay neurons were distinguished from local interneurons by their size, dendritic arborization pattern, and physiological characteristics such as a prominent calcium spike and a large $I_{\mathrm{h}}$ current (Steriade et al. 1997). Borosilicate glass electrodes (1.5-2.5 $\mathrm{M} \Omega$ ) were filled with an internal solution (315 mosM) containing (in mM) $35 \mathrm{CsF}, 100$ $\mathrm{CsCl}, 10$ EGTA, and 10 HEPES adjusted to $\mathrm{pH} 7.3$ with $\mathrm{CsOH}$ for voltage-clamp recordings. For current-clamp recordings, glass elec- trodes (2.8-3.5 $\mathrm{M} \Omega$ ) were filled with an internal solution (315 mosM) containing (in mM) 135 KGluconate, $5 \mathrm{NaCl}, 10$ HEPES, 0.5 EGTA, $2 \mathrm{MgSO}_{4}, 0.16 \mathrm{CaCl}_{2}, 4 \mathrm{Na}_{2} \mathrm{ATP}, 0.4 \mathrm{NaGTP}$, and 14 Tris-Creatine phosphate adjusted to $\mathrm{pH} 7.3$ with $\mathrm{KOH}$. A subset of current-clamp recordings was done with an internal solution (315 mosM) containing (in mM) $130 \mathrm{KMeSO}_{3}, 10 \mathrm{NaCl}, 2 \mathrm{MgCl}_{2}, 0.16 \mathrm{CaCl}_{2}, 0.5$ EGTA, 10 HEPES, $4 \mathrm{Na}_{2} \mathrm{ATP}, 0.4 \mathrm{NaGTP}$, and 14 Tris-Creatine phosphate adjusted to $\mathrm{pH} 7.3$ with $\mathrm{KOH}$. All recordings were perfomed at $34-36^{\circ} \mathrm{C}$ using an inline heater (Warner, Hamden, CT) while superfusing the slice with saline solution at $\sim 4 \mathrm{ml} / \mathrm{min}$.

Voltage-clamp recordings were performed using an Axopatch 200B (Axon Instruments, Foster City, CA) and filtered at $5 \mathrm{kHz}$. Currentclamp recordings were acquired in bridge mode and filtered at $10 \mathrm{kHz}$ with an AxoClamp 2B. Electrode capacitance was minimized by wrapping electrodes with parafilm (Sigma). The remaining electrode capacitance was compensated for with capacitance neutralization. Series resistances of $<20 \mathrm{M} \Omega$ were considered acceptable with the majority being in the range of $10-15 \mathrm{M} \Omega$ and were checked periodically by switching to the voltage-clamp mode of the AxoClamp2B. Bridge balance circuitry was used to compensate for electrode resistance. Capacitance neutralization was used to compensate for membrane capacitance in current-clamp mode. Compensation was checked periodically throughout the experiment.

Data were digitized at $20 \mathrm{kHz}$ with an ITC-18 interface (Instrutech, Port Washington, NY). Custom macros written for Igor Pro software (Wavemetrics, Lake Oswego, OR) were used for data analysis. Data are expressed as means \pm SE. Statistical analysis was performed with Igor Pro and SigmaStat software (V2.0, SPSS, Chicago, IL). Synaptic latencies varied between cells due to differences in the distance between recording and stimulating electrodes. Prior to generating average histograms of synaptically evoked responses, action potential timing was corrected for these differences by aligning the onset of the first excitatory postsynaptic potential (EPSP) in each cell.

\section{Stimulus pattern}

Glass electrodes filled with saline were used to stimulate axons of retinal ganglion cells within the optic tract. One electrode was placed in the optic tract and the other placed nearby to minimize stimulus artifacts. Relay neurons in p28-p33 mice receive input from only one to three retinal ganglion cells (Chen and Regehr 2000). When possible, stimulation location and intensity $(5-40 \mu \mathrm{A})$ were adjusted to activate a single RGC axon. In other cases, one strong input (amplitude at $-60 \mathrm{mV}, 600-3,000 \mathrm{pA}$ ) and an additional one to two weak inputs (amplitude at $-60 \mathrm{mV},<300 \mathrm{pA}$ ) were co-activated.

The stimulation pattern used was recorded from a mouse on retinal ganglion cell in response to a flash of light that turned on at time 0 and persisted for the length of the pattern (courtesy of Sheila Nirenberg, UCLA). We chose to examine responses to a single firing pattern for the following reasons. 1) Because we used slices obtained from young adult animals and recorded at near physiological temperatures, maintaining high-quality recordings over extended periods was a concern. It was also necessary to separate trials by $1.5 \mathrm{~min}$ to allow synaptic properties to recover to the same baseline. Therefore we limited the duration of the experiment by limiting the number of stimulus patterns tested to avoid problems with decreased quality of the recordings. 2) Our use of the dynamic-clamp technique enabled us to examine responses to controlled AMPA and NMDA component amplitudes and allowed us to manipulate synaptic plasticity in a way that is not possible with real synaptic inputs. However, this required that we used stimulus patterns that had first been used to characterize the NMDA and AMPA components of the responses in voltage clamp. We therefore studied a single firing pattern with properties that enabled us to investigate efficacy at the retinogeniculate synapse and that had been used to characterize the NMDA and AMPA components and their plasticity in voltage clamp. 


\section{Dynamic clamp}

Due to the necessity of a $\mathrm{K}^{+}$-based internal solution for currentclamp recordings, we could not quantify the amplitudes of AMPA and NMDA currents in voltage clamp to correlate AMPA/NMDA amplitudes and ratios with differences in relay neuron responses. We therefore used the dynamic-clamp technique to simulate synaptic activation and examine population responses with controlled synaptic current amplitudes.

Conductance waveforms were calculated from voltage-clamp recordings at $34-37^{\circ} \mathrm{C}$ of pharmacologically isolated AMPA and NMDA excitatory postsynaptic currents (EPSCs) that were elicited with the same stimulation pattern used in this study. The EPSCs recorded under control conditions were influenced by presynaptic depression, AMPA receptor desensitization and NMDA receptor saturation, and therefore these forms of plasticity were included in our calculated conductance trains. Dynamic-clamp calculations were carried out separately for AMPA and NMDA conductances.

AMPA conductances were injected using an ITC-18 board configuration designed by Instrutech operating at $20 \mathrm{kHz}$ and custom macros written for Igor Pro software. AMPA current was calculated as

$$
I_{\mathrm{AMPA}}(t)=g_{\mathrm{AMPA}}(t) *\left(V_{\mathrm{m}}(t)-E_{\mathrm{REV}}\right)
$$

where $I_{\mathrm{AMPA}}$ is the current to be injected, $g_{\mathrm{AMPA}}$ is the conductance waveform determined from voltage-clamp recordings at a holding potential of $-70 \mathrm{mV}, V_{\mathrm{m}}$ is the membrane potential, and $E_{\mathrm{rev}}$ is the reversal potential, which is $0 \mathrm{mV}$ for AMPA. To simulate the absence of desensitization of AMPA receptors, excitatory postsynaptic conductances (EPSGs) were scaled to the average EPSC amplitudes recorded when desensitization was prevented with cyclothiazide (Chen et al. 2002). To simulate no plasticity, peak AMPA EPSG amplitude was kept constant throughout the train.

NMDA conductances were injected using custom written macros for Igor Pro software running on a Windows 98 or 2000 PC platform and a NIDAQ BNC-2090 data acquisition board operating at 2.5 or 5 $\mathrm{kHz}$ (National Instruments, Austin, TX). NMDA current was calculated as

$$
I_{\mathrm{NMDA}}(t)=g_{\mathrm{NMDA}}\left(t, V_{\mathrm{m}}(t)\right) *\left(V_{\mathrm{m}}(t)-E_{\mathrm{REV}}\right)
$$

where $g_{\mathrm{NMDA}}$ is the conductance waveform measured in response to the stimulus train in voltage clamp. The voltage dependence of the NMDA component was characterized in voltage-clamp experiments at $34-36^{\circ} \mathrm{C}$. As shown in Fig. $1 C$, the peak EPSCs showed the characteristic voltage dependence of the NMDA receptor. To account for its voltage dependence, the NMDA conductance at each time point was scaled according to a lookup table determined from Fig. $1 C$ with intervening points determined by linear interpolation. In addition, the time course of the NMDA response evoked by single stimuli was voltage dependent and varied from a half decay time of $16.0 \pm 1.8 \mathrm{~ms}$ at $-55 \mathrm{mV}$ to $30.9 \pm 2.2 \mathrm{~ms}$ at $+40 \mathrm{mV}(n=6)$. The time course of the response evoked by the train was also voltage dependent, although the differences were less pronounced at the end of the train. We tested conductances that had been measured both at $-55 \mathrm{mV}(n=6$ cells $)$ and $+40 \mathrm{mV}$ ( $n=5$ cells) and found that while the same qualitative contribution was observed at both potentials, the longer-lasting conductance at $+40 \mathrm{mV}$ was slightly more efficacious. In Fig. 5, the conductance waveform measured at $+40 \mathrm{mV}$ was used, and in Figs. $7-10$, the conductance waveform measured at $-55 \mathrm{mV}$ was used.

AMPA and NMDA currents were summated with a Frequency Devices 900 amplifier prior to being relayed to the AxoClamp 2B amplifier. Dynamic-clamp current injection trials were separated by 10 -s intervals. The order of AMPA and NMDA conductance combinations was randomized for each cell.
A

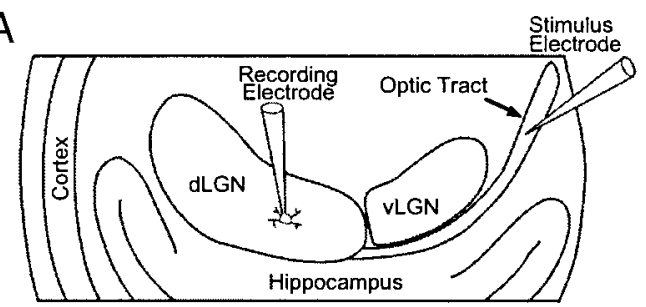

B

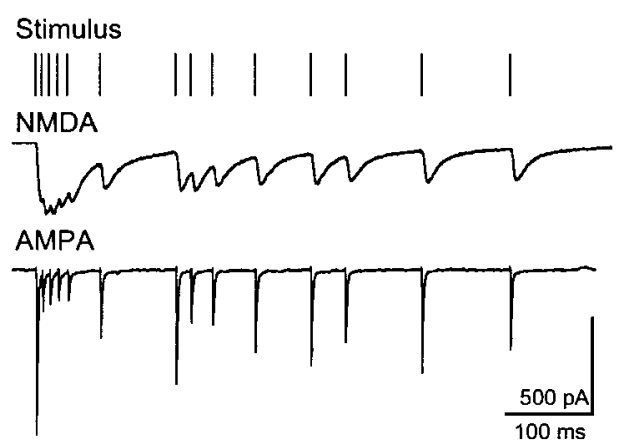

C

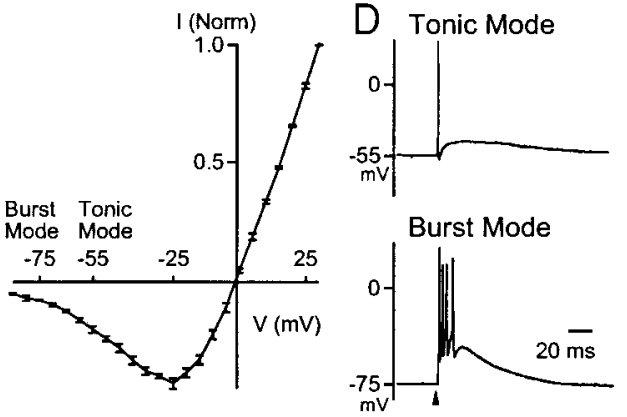

FIG. 1. Properties of the retinogeniculate synapse. $A$ : schematic illustration of the pseudo-sagittal brain slice preparation. Relay neurons were recorded in the dorsal lateral geniculate nucleus (dLGN). The axons of retinal ganglion cells were stimulated within the optic tract. $B$ : isolated $N$-methyl-D-aspartate (NMDA, top; $10 \mu \mathrm{M}$ NBQX, holding potential $=-55 \mathrm{mV}$ ) and AMPA (bottom; $5 \mu \mathrm{M}$ CPP, holding potential $=-70 \mathrm{mV}$ ) EPSCs elicited by retinogeniculate synapse activation are shown. The stimulation pattern is indicated by vertical bars above the recordings. Top and bottom traces were recorded in different cells. The recording of AMPA excitatory postsynaptic currents (EPSCs) is adapted from Chen et al. (2002). C: the voltage dependence of the NMDA current is plotted as the average peak NMDA EPSC amplitude normalized to EPSC amplitude $( \pm \mathrm{SE})$ at $+30 \mathrm{mV}(n=3)$. Membrane potentials that were used to mimic burst $(-75 \mathrm{mV})$ and tonic $(-55 \mathrm{mV})$ mode are indicated. $D$ : example relay neuron responses at $-55 \mathrm{mV}$ (top) and $-75 \mathrm{mV}$ (bottom) to a single stimulation occurring at the time indicated by the arrowhead. The same neuron is shown in the top and bottom. Scale bar applies to both recordings.

\section{RE S U L T S}

Whole cell voltage-, current-, and dynamic-clamp recordings were made from LGN relay neurons in pseudo-sagittal thalamic slices (Fig. 1A). Experiments were performed at near physiological temperatures in young adult mice (p28-p33). At this age, the majority of synapse elimination has occurred (Chen and Regehr 2000), and relay cells receive one to three synaptic inputs. This allowed us to assess the response of relay cells to individual RGC inputs. The firing patterns of RGCs are dependent on the type of retinal ganglion cells and the visual stimulus. We activated RGC inputs with a stimulus pattern recorded from a mouse retinal ganglion cell in response to a flash of light (Fig. 1B, top). This pattern, which began with a burst followed by irregular firing, provided a useful way to 
examine synaptic factors controlling relay neuron responses to RGC activity.

Our previous characterization of the AMPA and NMDA EPSCs evoked by this stimulation pattern (Chen et al. 2002) demonstrated properties of the retinogeniculate synapse that are likely to play important roles in shaping relay neuron responses. Example recordings of pharmacologically isolated NMDA and AMPA currents illustrate the differences in time course and plasticity of these two components (Fig. 1B, bottom). AMPA EPSCs are short-lived and are depressed in a use-dependent manner. This reflects presynaptic depression and AMPA receptor desensitization (Chen et al. 2002). NMDA EPSCs are much longer lived, and short-term plasticity arises from presynaptic depression and NMDA receptor saturation (Chen et al. 2002). In addition, the NMDA component displays a voltage dependence typical for this receptor channel complex (Fig. 1C) (Mayer and Westbrook 1987). Thus we aimed to determine how these distinct properties of the AMPA and NMDA components contribute to RGC activation of relay neurons.

Additionally, we wanted to examine how synaptic properties interact with response mode to influence transmission at the retinogeniculate synapse. Therefore we performed all of our experiments with relay neurons that were initially at either -55 or $-75 \mathrm{mV}$ to simulate tonic and burst mode, respectively. Relay neurons typically had resting potentials of approximately $-60 \mathrm{mV}$. By manually injecting small currents ( $\pm 5-80 \mathrm{pA})$, we adjusted their resting potentials to mimic tonic and burst mode. At $-55 \mathrm{mV}$, relay neurons responded to a single stimulus with an excitatory postsynaptic potential (EPSP) that usually elicited one (Fig. 1D, top) or occasionally two action potentials, mimicking tonic mode. However, with neurons at -75 $\mathrm{mV}$, the same single stimulus elicited an EPSP that reached threshold for a low-threshold calcium spike (large depolarization) and a burst of several high-frequency sodium action potentials, thereby mimicking burst mode (Fig. 1D, bottom). Similar voltage-dependent effects corresponding to the transition between tonic and burst mode were seen in 23 of 23 cells tested.

\section{Relay neuron responses evoked by RGC stimulation}

Stimulation of RGC inputs with the same temporal pattern elicited distinct responses in different relay neurons. Example responses evoked at $-55 \mathrm{mV}$ in three different neurons are shown (Fig. 2A). Some relay neurons fired one to a few action potentials throughout the train (cell 1), some fired action potentials quite faithfully in response to each EPSP (cell 2), while others responded with multiple action potentials per EPSP (cell 3 ). For a single neuron, the response pattern was consistent as indicated in raster plots of two to three trials below each recording (Fig. 2A).

The average of all responses is summarized in a histogram with a bin size of $1 \mathrm{~ms}$ (Fig. $2 B ; n=16$ cells, $2-3$ trials/cell). Relay neurons have an absolute refractory period $>1 \mathrm{~ms}$. Therefore in the average data, a bin height of 1 indicates an action potential occurred in every trial in every cell within that $1 \mathrm{~ms}$ bin. The first EPSP of the train was more effective at firing relay neurons than subsequent EPSPs. Each EPSP was more likely to elicit a single action potential with a short latency (tall bin after each stimulus) than to elicit additional
Tonic Mode
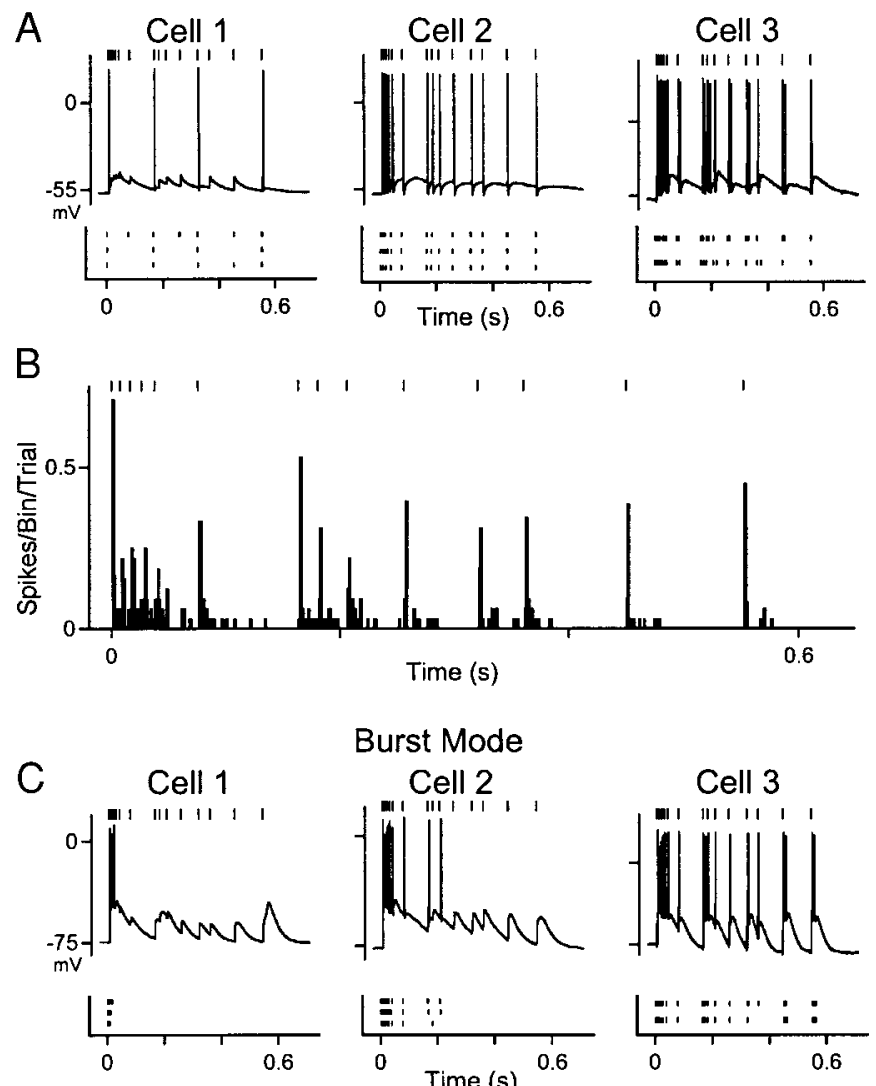

Burst Mode
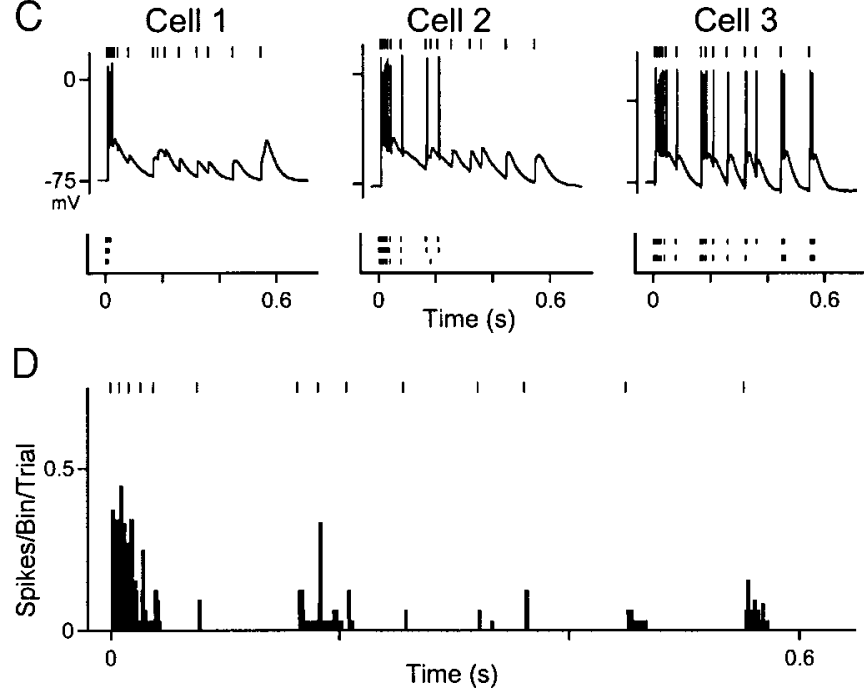

FIG. 2. Response of relay neurons to activation of retinogeniculate synapses. Example recordings of 3 relay neurons are shown at $-55 \mathrm{mV}(A)$ and $-75 \mathrm{mV}(C)$. The vertical bars above recordings indicate the stimulation pattern. Below each recording is a raster plot of 2 or 3 trials including the example trial with each vertical bar representing an action potential. The average number of action potentials per bin $(1 \mathrm{~ms})$ per trial $(2-3$ per cell) is plotted for responses elicited at $-55 \mathrm{mV}(B)$ and $-75 \mathrm{mV}(D)$. The stimulation pattern is indicated by vertical bars at top of graphs. Responses were measured in the same neurons for $A$ and $C$ and in the same group of neurons for $B$ and $D(n=16)$.

action potentials with longer latencies (short bins after each tall bin).

The responses at $-75 \mathrm{mV}$ were markedly different from those at $-55 \mathrm{mV}$ with the most prominent feature being a burst of action potentials at the beginning of the train (Fig. 2C). The burst of sodium spikes always occurred at the peak of a large depolarization that decayed within $\sim 100 \mathrm{~ms}$. This depolarization likely reflects a low-threshold calcium spike (Jahnsen and Llinas 1984a,b).

At $-75 \mathrm{mV}$, the stimulus train also elicited distinct responses in different relay neurons. Some relay neurons fired a single burst (cell 1), some fired an initial burst followed by a variable 
number of single spikes (cell 2), and others fired multiple bursts throughout the train (cell 3). Again, the response was consistent within a cell, illustrated by the raster plots below the recordings (Fig. 2C). The average histogram reveals that most action potentials occurred during the initial burst $(n=16,2-3$ trials/cell; Fig. 2D). Later in the train, one to a few action potentials were elicited by each EPSP in a subset of relay neurons. In all cases, action potentials elicited at $-75 \mathrm{mV}$ did not follow the stimulation pattern in a one-for-one manner.

\section{Pharmacological dissection of synaptically evoked responses}

In the remainder of this study, we address the contributions of different synaptic mechanisms to relay neuron responses. We first examined the relative contributions of AMPA and NMDA currents by selectively eliminating each one pharmacologically.

Bath application of the NMDA antagonist CPP $(5-10 \mu \mathrm{M})$ decreased the number of action potentials at -55 and $-75 \mathrm{mV}$ (Fig. 3, $A$ and $B$ ). In an example experiment at $-55 \mathrm{mV}$, a raster plot of several trials before, during, and after CPP application demonstrates the decrease in action potential number was reversible (Fig. 3A). CPP application resulted in faster, smaller EPSPs (Fig. 3B). Although CPP always decreased the overall number of action potentials, the responses at $-55 \mathrm{mV}$ could vary from a single action potential to fairly reliable shortlatency responses throughout the train (Fig. $3 B$ ). At $-75 \mathrm{mV}$, CPP application decreased the number of action potentials, but calcium spikes remained in the majority of neurons (Fig. $3 B$, bottom, $n=6 / 7)$. There was little change in the shape of the subthreshold component of the responses, probably owing to the contributions of the low-threshold calcium channels both with and without CPP (Fig. 3B).

We next examined the influence of blocking the AMPA component. The AMPA receptor antagonist NBQX $(5-10 \mu \mathrm{M})$ decreased the number of action potentials elicited by the stimulus train at both -55 and $-75 \mathrm{mV}$. This decrease in action potential number was reversible (Fig. $3 C$ ). Although there was variability in the control responses, NBQX always reduced the responses at $-55 \mathrm{mV}$. In the absence of the AMPA component, the responses consisted primarily of action potentials early in the stimulus train (Fig. 3D, top). At $-75 \mathrm{mV}$ in NBQX, the response consisted of either no action potentials (Fig. 3D, bottom; $n=4 / 6$ ) or a few action potentials during an initial burst $(n=2 / 6)$. In a subset of experiments, we followed NBQX application with a co-application of NBQX and CPP, which completely blocked synaptic transmission $(n=4$, data not shown).

To compare more directly the role of AMPA and NMDA receptors, we determined the average responses during control conditions and during blockade of each receptor type (Fig. 4). At $-55 \mathrm{mV}, \mathrm{NBQX}$ significantly decreased the total number of action potentials throughout the train from $12.8 \pm 4.8$ to $3.6 \pm$ $2.1(n=6 ; 21 \pm 11 \%$ of control; $t=-6.98, P<0.01$; Fig. $4 A a$ ). CPP also significantly reduced the number of action potentials evoked by the stimulus train, from $10.1 \pm 3.1$ to $4.9 \pm 1.9(n=7 ; 53 \pm 13 \%$ of control; $t=-3.59, P<0.01)$. However, the remaining response was quite different from that in NBQX (Fig. 4A, $a$ and $b$, right). CPP eliminated the longlatency responses that occurred several milliseconds after each stimulus but did not affect the short-latency responses.
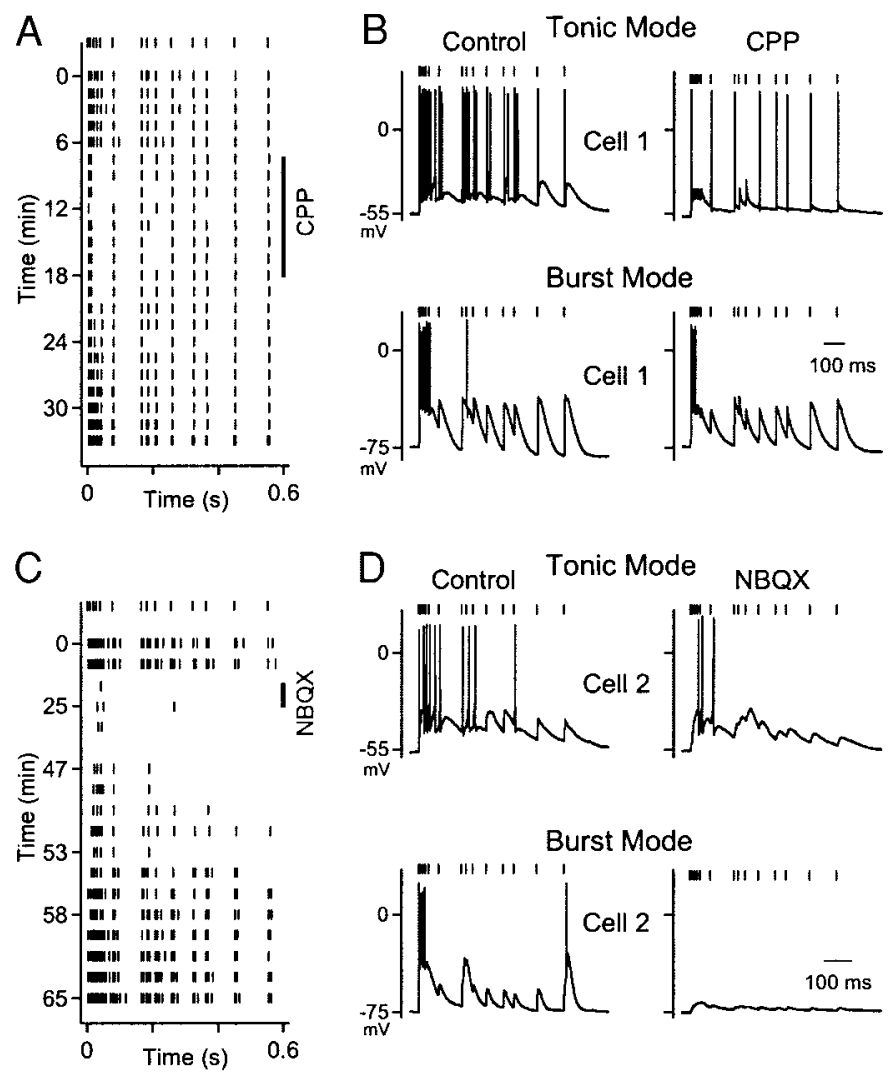

FIG. 3. NMDA and AMPA receptor blockade each decreased relay neuron responses to retinogeniculate synaptic stimulation. Raster plots indicate the timing of synaptically evoked action potentials for successive trials before, during and after CPP application $(A)$ and NBQX application $(C)$. Recordings of representative relay neurons illustrate responses in control conditions and during bath application of CPP at $-55 \mathrm{mV}(B$, top $)$ and $-75 \mathrm{mV}(B$, bottom $)$ and NBQX at $-55 \mathrm{mV}(D$, top $)$ and $-75 \mathrm{mV}(D$, bottom). Scale bars apply to top and bottom. Stimulus pattern is indicated by vertical bars above raster plots and recordings.

Some aspects of the effects of these two antagonists on responses in tonic mode were more evident when the evoked responses were examined on an expanded time scale (Fig. 4B). Here we took 15-ms windows beginning with the onset of each of the final nine stimuli in the train and averaged the responses during these windows for each condition. We chose the last nine stimuli as these had sufficiently long inter-stimulus intervals (17-102 ms) to enable us to examine long- and shortlatency action potentials without overlap into the subsequent stimulus. In control conditions, the majority of action potentials occurred within the first $3 \mathrm{~ms}$ following each stimulus, although action potentials were also elicited at longer latencies (Fig. 4B, $a$ and $b$, left). NBQX decreased the number of short-latency action potentials (Fig. 4Ba, right). CPP, however, eliminated longer-latency action potentials without significantly affecting the first $3 \mathrm{~ms}$ of the response (Fig. $4 \mathrm{Bb}$, right).

At $-75 \mathrm{mV}, \mathrm{CPP}$ and NBQX also decreased the total number of action potentials elicited by the stimulus train. NBQX significantly reduced the number of action potentials from $8.3 \pm 1.6$ to $1.8 \pm 1.1(n=6 ; 19 \pm 13 \%$ of control; $t=-6.24, P<0.01)$. In NBQX, there were only a few action potentials elicited with none occurring after the initial burst (Fig. 4Ca). CPP significantly decreased the number of action potentials from $9.1 \pm 2.2$ to $4.7 \pm 1.8(n=7 ; 46 \pm$ 

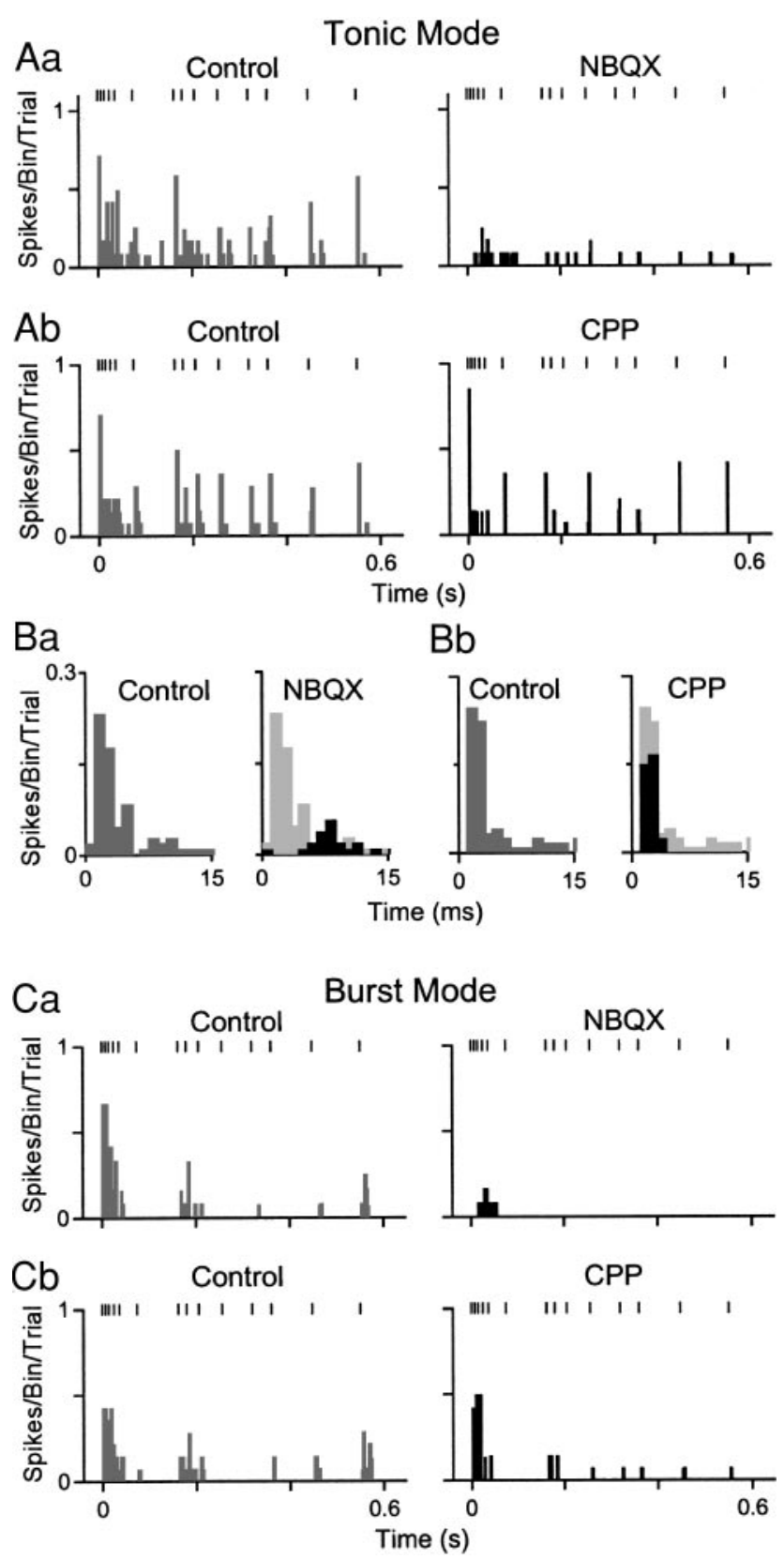

FIG. 4. Summary of the effects of AMPA and NMDA receptor blockade on relay neuron responses. The average relay neuron responses evoked by retinogeniculate synaptic activation at $-55 \mathrm{mV}(A$ and $B)$ and $-75 \mathrm{mV}(C)$ are shown during control conditions and during application of NBQX ( $A a$, $B a$, and $C a)$ or CPP $(A b, B b$, and $C b) . A$ and $C$ : the average number of action potentials per bin ( $1 \mathrm{~ms}$ bins) per trial is plotted for each condition. The vertical bars above the histograms represent the stimulation pattern. $B$ : average poststimulus time histograms of the final 9 stimuli in the train for control ( $\square$ ) and drug application $(\square)$ at $-55 \mathrm{mV}$. The same set of neurons was recorded in $A-C$ for NBQX experiments $(n=6)$. A separate population of neurons was recorded for CPP experiments in $A-C(n=7)$. Data in $B$ are re-plotted from $A$.

$10 \%$ of control; $t=-5.45, P<0.01 ;$ Fig. $4 C b)$. The effects of CPP were more subtle than those of NBQX, consistent with a smaller contribution of the NMDA component at -75 $\mathrm{mV}$ due to the voltage dependent $\mathrm{Mg}^{2+}$ block (Fig. 1C). Thus pharmacological separation of the these two components demonstrates both AMPA and NMDA receptors contribute to relay neuron responses in tonic and burst mode with differences in the timing and strength of their influences.

Investigating contributions to relay neuron responses with dynamic clamp

Our experiments revealed several aspects of AMPA and NMDA contributions to relay neuron responses in tonic and burst mode. However, variability in the amplitudes of synaptic currents in different neurons complicates the analysis of the role of synaptic plasticity and the AMPA and NMDA components in eliciting responses. We therefore turned to the dynamic-clamp technique to examine responses to controlled AMPA and NMDA component amplitudes as well as to manipulate synaptic plasticity in a manner that is not possible with real synaptic inputs.

An example of a dynamic-clamp experiment is shown in Fig. 5. Conductance waveforms were calculated from AMPA and NMDA currents measured in voltage clamp (Figs. 5A $a$ and $1 B$; see METHODS). The current injected (Fig. 5Ab) depended on the conductance waveforms and on the voltage dependence. A linear voltage dependence was used for the AMPA component, and the voltage dependence of the NMDA component was determined from Fig. 1C. Because currents were injected in current clamp mode, a positive current reflects a depolarizing current, whereas a negative current reflects a hyperpolarizing one. In this example, the total current injected (Fig. 5Ab, bottom) elicited the voltage response shown in Fig. 5Ac (dynamic clamp) in a neuron with an initial membrane potential of $-55 \mathrm{mV}$.

We compared the responses to dynamic-clamp activation and RGC stimulation in the same neuron. The simulated conductance amplitudes shown (Fig. 5Aa) and real RGC activation elicited responses that were remarkably similar (Fig. 5Ac). Although there were some differences in action potential timing, these differences are well within the trial-to-trial variability observed during real synaptic stimulation (see Fig. 2). The same amplitude conductances also elicited a response (dynamic clamp) that mimicked the response to real synaptic stimulation (synaptic) at $-75 \mathrm{mV}$ (Fig. 5B).

The similarities of dynamic-clamp-evoked and synaptically evoked responses suggest that dynamic clamp is a useful tool to address the role of synaptic factors in shaping relay neuron responses. This good agreement likely reflects the location of retinogeniculate synapses on the proximal dendrites of relay neurons and the electrotonically compact nature of relay neurons (Bloomfield et al. 1987; Crunelli et al. 1987; Hamos et al. 1987). Thus the dynamic-clamp technique allowed us to simulate AMPA and NMDA currents in a realistic manner and control aspects of the synaptic plasticity as well as the amplitudes and the ratio of the two components.

\section{Investigating the influence of synaptic plasticity on relay neuron responses}

We first examined how use-dependent plasticity contributes to the role of AMPA receptors in relay neuron responses. In the preceding text, we found that in the presence of CPP, AMPA current elicited an initial action potential in the majority of trials. However, it did not elicit action 

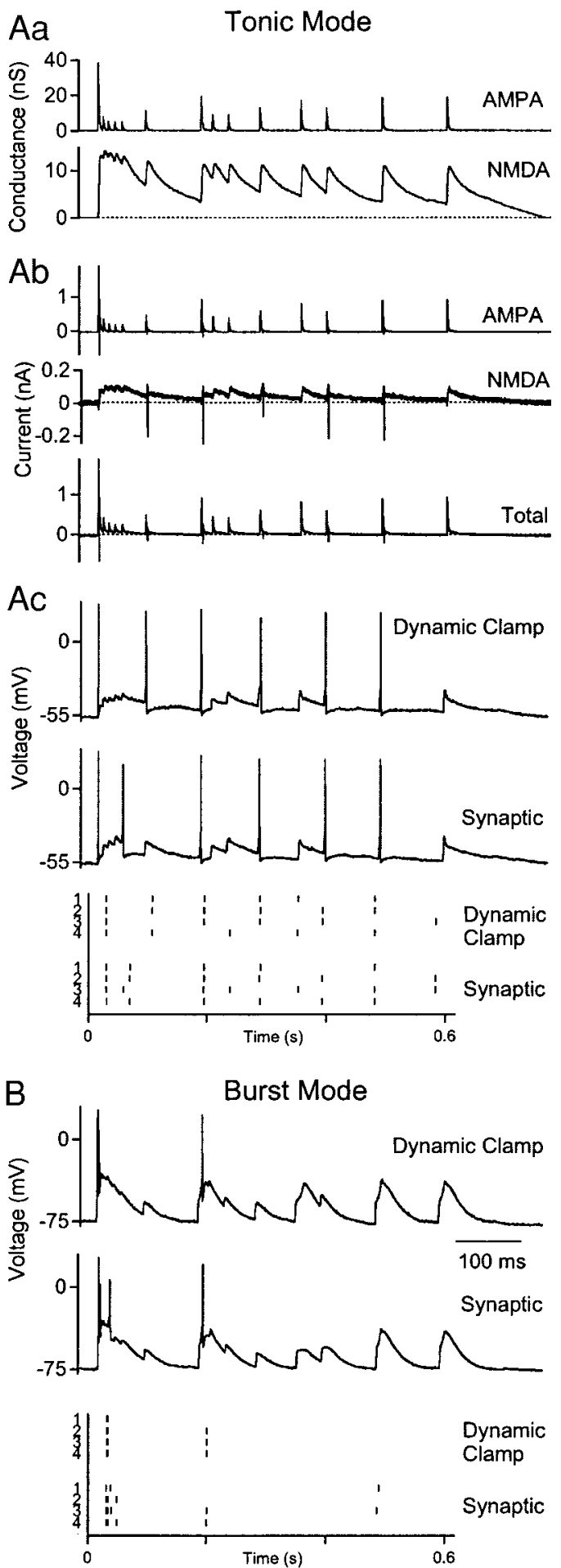

FIG. 5. Dynamic-clamp AMPA and NMDA conductances mimic synaptically evoked relay neuron responses. A comparison of relay neuron responses to simulated and evoked synaptic currents is shown in an example cell. The AMPA and NMDA conductances $(A a)$ used to simulate synaptic currents and the resulting currents $(A b)$ are shown. $A c$, top: relay neuron voltage was recorded during injection of the preceding currents (dynamic clamp) and in response to retinogeniculate synaptic activation (synaptic). Ac, bottom: raster plot indicates action potentials elicited during 4 trials of dynamic-clamp current injection and 4 trials of synaptic stimulation. The amplitudes of AMPA and NMDA conductances shown here were chosen to mimic the synaptic response recorded. $B$ : responses to dynamic-clamp input and synaptic input and raster plots of repeated trials in the same relay neuron as $A$ at an initia potential of $-75 \mathrm{mV}$ are shown. The same conductances were used in $A$ and $B$.

\section{A Desens + Depression \\ Depression No Plasticity}
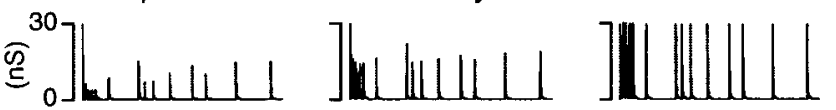

B
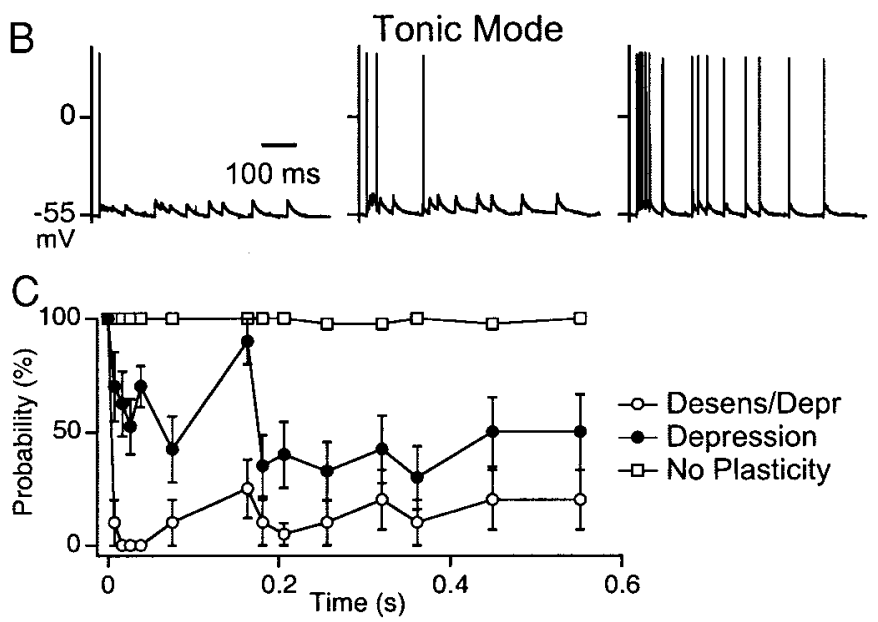

D

Burst Mode

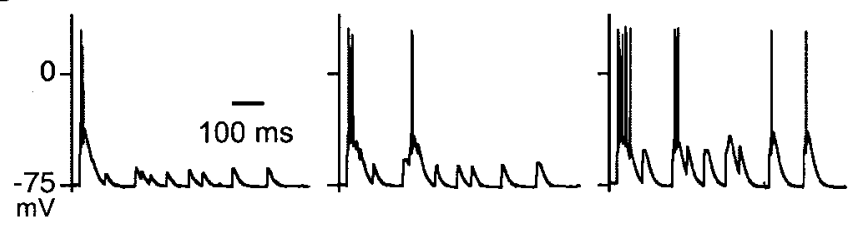

FIG. 6. Dynamic-clamp recordings illustrate the role of desensitization and depression in shaping relay neuron responses to retinogeniculate synaptic activation. A: traces indicate AMPA conductances with desensitization and depression, depression only, or no plasticity that were used to simulate synaptic inputs. Conductances were determined from voltage-clamp data (see METHODS). Relay neuron recordings illustrate example responses under the 3 plasticity conditions at $-55 \mathrm{mV}(B)$ and $-75 \mathrm{mV}(D)$. C : average probability ( \pm $\mathrm{SE}$ ) of each stimulus in tonic mode is plotted against time for the 3 plasticity conditions. The same neurons were used in all 3 conditions at both membrane potentials ( $n=10$ cells, 4 trials/cell).

potentials as faithfully during the high-frequency portion of the train. This is consistent with previous studies demonstrating that AMPA receptors alone cannot maintain sustained responses to optic tract or visual stimulation (Hartveit and Heggelund 1990; Kwon et al. 1991; Turner et al. 1994). Previously, we showed that AMPA currents are influenced by both presynaptic depression and postsynaptic receptor desensitization (Chen et al. 2002). Here we test whether these forms of plasticity can account for the abbreviated relay neuron responses. Voltage-clamp measurements of AMPA currents (Chen et al. 2002) served as the basis for our conductance waveforms in control conditions when desensitization and depression are both present (Fig. 6A, left), when depression alone is present (Fig. 6A, middle), and when no plasticity occurred (Fig. 6A, right). A peak AMPA conductance of $30 \mathrm{nS}$ was used in each case.

Relay neuron responses to these three stimulus trains revealed the important contributions of desensitization and depression to responses at $-55 \mathrm{mV}$. The recordings in Fig. $6 B$ illustrate example responses elicited in tonic mode during each plasticity condition. For all conditions tested, the initial EPSP almost always evoked a spike in the relay neuron (Fig. 6B). 
However, the efficacy of subsequent EPSPs in the train was sensitive to the plasticity. The plot of average probability of each stimulus eliciting a spike illustrates that desensitization decreased efficacy most dramatically during the early portion of the train when the firing frequency was highest (Fig. $6 C$; $n=10$ cells, 4 trials/cell). This is not surprising considering the much faster recovery from desensitization compared with presynaptic depression (Chen et al. 2002). Throughout the train depression also limited efficacy, while without plasticity, each AMPA EPSP was highly effective at triggering an action potential (Fig. 6, $B$ and $C$ ). Elimination of desensitization and desensitization plus depression resulted in significant increases in efficacy $(P<0.05$; 1 -way ANOVA and Tukey $t$-test). On average each EPSP evoked an action potential with an efficacy of $11.5 \pm 8.3 \%$ when depression and desensitization were present, $51.4 \pm 11.5 \%$ when only depression was present, and $99.4 \pm 0.6 \%$ when there was no plasticity (Fig. $6 C ; n=10$ cells, 4 trials/cell).

Plasticity of AMPA currents also influenced the overall strength of relay neuron responses at $-75 \mathrm{mV}$. The control response with desensitization and depression present consisted primarily of an initial burst (Fig. $6 D$, left) that was stronger with depression only (Fig. $6 D$, middle) and even stronger with no plasticity (Fig. $6 D$, right). Because of the nonlinear nature of responses in burst mode, we measured the total number of action potentials elicited by the stimulus train instead of the efficacy of individual stimuli. Elimination of desensitization plus depression caused a significant increase in action potential number $(P<0.05 ; 1$-way ANOVA and Tukey $t$-test). The number of action potentials increased from $6.0 \pm 1.5$ when desensitization and depression were present to $9.7 \pm 1.9$ with depression only and to $13.5 \pm 2.1$ with no plasticity present ( $n=10$ cells, 4 trials/cell). The most prominent change at -75 $\mathrm{mV}$ was an increased strength of the initial burst, although there were also some action potentials elicited later in the train, particularly with no plasticity present. Therefore synaptic plasticity that influences the AMPA component severely limits the ability of AMPA currents to effectively elicit relay neuron firing during high-frequency activity.

Investigating the relative contributions of $A M P A$ and NMDA using dynamic clamp

The dynamic-clamp technique also enabled us to examine details of the relative contributions of AMPA and NMDA conductances to relay neuron responses by examining responses among neurons to the same amplitudes of AMPA and NMDA conductances. We began by determining the contributions of AMPA and NMDA conductances to the total number of action potentials elicited throughout the stimulus train. Peak conductances were varied between 10 and $40 \mathrm{nS}$, which is within the range of real RGC conductances we observed.

NMDA conductances made larger contributions to action potential number than AMPA conductances. Small isolated NMDA conductances $(10,20 \mathrm{nS})$ did not elicit action potentials. However, higher NMDA conductances $(30,40 \mathrm{nS})$ evoked action potentials even in the absence of an AMPA conductance (Fig. 7A, $\bigcirc ; n=6$ ). Our stimulus train consisted of 14 stimuli and, as indicated in Fig. 7A, 30 and $40 \mathrm{nS}$ peak NMDA conductances elicited one to two action potentials per stimulus. The addition of a $40 \mathrm{nS}$ AMPA conductance in- creased the number of action potentials throughout the train, most notably at low NMDA conductances (Fig. 7A, •). Isolated AMPA conductances elicited few action potentials at all values (Fig. 7B, ○). When a $40 \mathrm{nS}$ NMDA conductance was added, many more action potentials were elicited at each AMPA conductance value (Fig. $7 B, \bullet ; n=6$ ).

Our pharmacological experiments indicated differences in the timing of the action potentials elicited in tonic mode by AMPA and NMDA currents. To examine this issue more

\section{Tonic Mode}

A

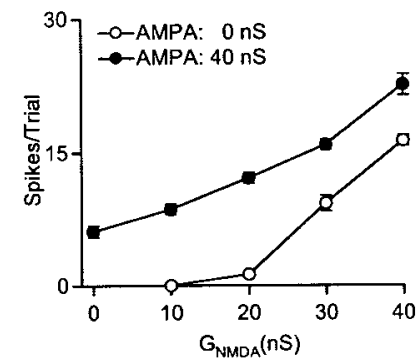

$\mathrm{B}$
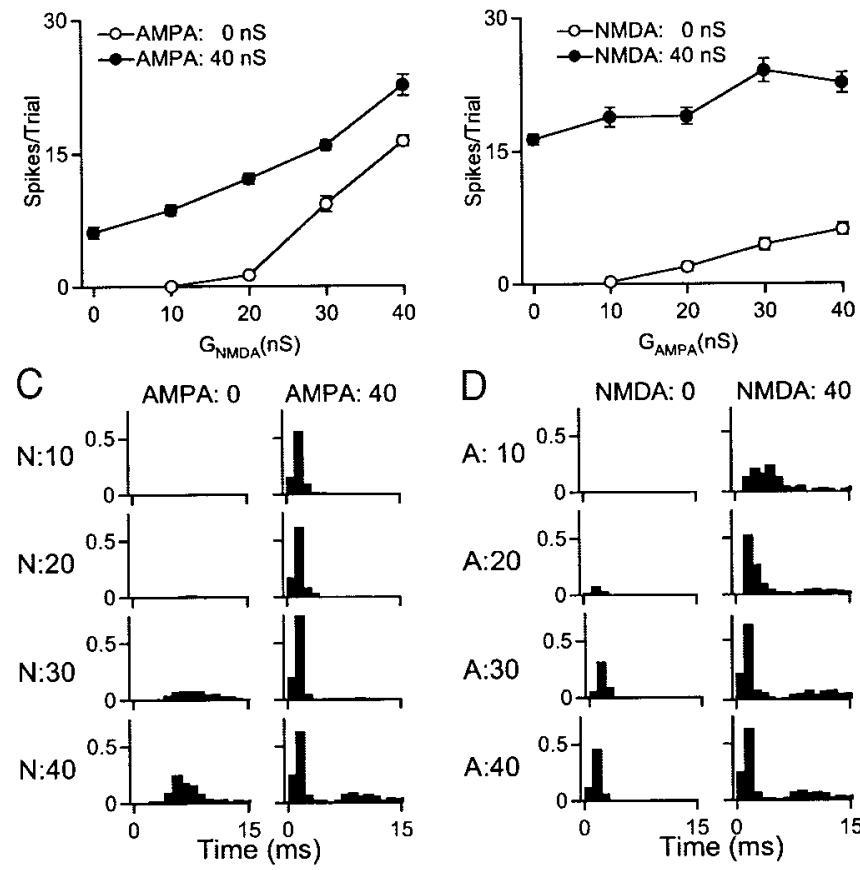

D NMDA: 0 NMDA: 40

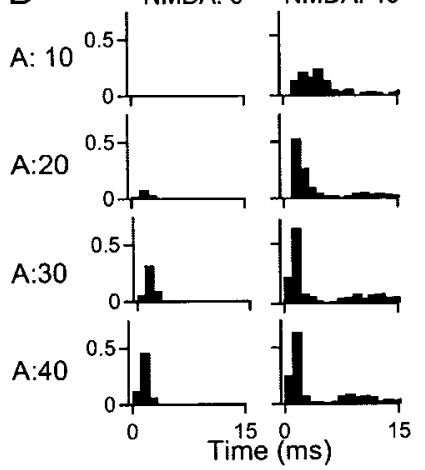

\section{Burst Mode}
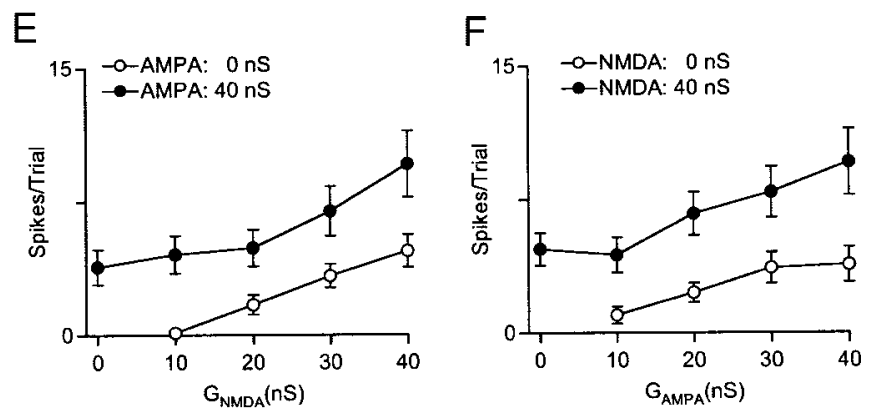

FIG. 7. The roles of the NMDA and AMPA components in shaping the responses of relay neurons to retinogeniculate activation. Dynamic-clamp recordings were used to activate relay neurons with an artificial retinogeniculate synaptic input. $A$ and $B$ : the average number of action potentials elicited per trial is summarized for each of the indicated conditions. The peak NMDA component was varied from 0 to $40 \mathrm{nS}$ with peak AMPA conductance at either 0 or $40 \mathrm{nS}$ in cells at $-55 \mathrm{mV}(A)$. The peak AMPA component was varied from 0 to $40 \mathrm{nS}$ with peak NMDA conductance at either 0 or $40 \mathrm{nS}$ in cells at $-55 \mathrm{mV}(B) . C$ and $D$ : average poststimulus time histograms of the final 9 stimuli in the train are summarized for responses elicited at $-55 \mathrm{mV}$ by injection of the indicated NMDA and AMPA conductances (N, NMDA; A, AMPA). $E$ and $F$ : the average number of action potentials elicited per trial with neurons at $-75 \mathrm{mV}$ is summarized for the indicated AMPA and NMDA conductances. Summaries are based on 6 and 5 cells for tonic and burst mode, respectively. 
carefully, we compared the contributions of controlled amplitudes of dynamic clamp AMPA and NMDA currents at -55 $\mathrm{mV}$. Data were plotted as average histograms on an expanded time scale (Fig. 7, $C$ and $D$ ). As in Fig. 4B, the responses during the first $15 \mathrm{~ms}$ following each of the last nine stimuli were averaged together. Even though each stimulus evoked on average more than one action potential for NMDA conductances of 30 and $40 \mathrm{nS}$, the responses were not precisely timed across trials and had long latencies $(4-8 \mathrm{~ms}$, Fig. $7 C$, left). The addition of a $40 \mathrm{nS}$ AMPA conductance reduced the action potential latency to 1- $2 \mathrm{~ms}$ and improved the precision (Fig. $7 C$, right). For NMDA conductance values that elicited very few spikes in isolation, the addition of an AMPA conductance resulted in short latency action potentials (Fig. $7 C ; n=6$ cells, 4 trials/cell). For 30 and $40 \mathrm{nS}$ NMDA conductances, the addition of an AMPA conductance had less of an effect on the total number of action potentials (Fig. 7A) but greatly decreased the latency and increased the precision (Fig. $7 C$ ). Note the large early peak and the decrease in the later peak when 40 nS AMPA was added (Fig. 7C, right).

When we instead began with isolated AMPA current, we found that only short-latency action potentials with reliable timing were elicited (Fig. 7D, left). The addition of a $40 \mathrm{nS}$ NMDA conductance increased the number of both short- and long-latency spikes (Fig. 7D, right; $n=6$ cells, 4 trials/cell). As discussed in the preceding text, this addition of NMDA conductance greatly increased the total number of action potentials at all AMPA conductance values (Fig. 7B).

In burst mode, responses to AMPA and NMDA dynamicclamp conductance combinations were dominated by bursts of activity that did not faithfully follow the stimulus pattern as we observed with real synaptic input. We found that despite the voltage-dependent block of NMDA currents, isolated NMDA conductances (20-40 nS) elicited action potentials when neurons were initially at $-75 \mathrm{mV}$ (Fig. $7 E$, $\bigcirc$ ). These responses consisted primarily of bursts of action potentials, likely elicited by activation of low-threshold calcium spikes (Jahnsen and Llinas 1984a,b). Adding a $40 \mathrm{nS}$ AMPA conductance lowered the NMDA conductance threshold for bursts and increased the average number of total action potentials at all NMDA conductance values (Fig. $7 E, \bullet ; n=5$ cells, 4 trials/cell).

Isolated AMPA conductances were also able to activate low-threshold calcium spikes and a burst of action potentials ( $n=5$ cells, 4 trials/cell). The AMPA conductance elicited action potentials at all AMPA conductance values whether alone (Fig. $7 F, \bigcirc$ ) or in combination with a $40 \mathrm{nS}$ NMDA conductance (Fig. $7 F, \bullet$ ).

\section{Investigating amplification during tonic mode}

It is not surprising that multiple action potentials can be elicited by a single stimulus in burst mode. However, the preceding analysis indicated that multiple action potentials could also be elicited by individual stimuli when neurons were in tonic mode. To examine this issue quantitatively, we measured the percentages of times each stimulus of the train evoked zero, one, two, or more action potentials (Fig. 8A). These data were averaged for all stimuli in the train and plotted as percentages for each quantity of action potentials for different combinations of AMPA and NMDA conductances $(n=6$ cells, 4 trials/cell). Small NMDA conductances usually failed to evoke a response (Fig. $8 B$ ). As the size of the NMDA conductance was increased, most stimuli elicited one or two action potentials. The addition of a 40-nS AMPA conductance increased the number of stimuli that elicited one action potential, particularly at low NMDA values. At higher NMDA conductances, about half of the stimuli elicited two action potentials (Fig. $8 C$ ). During injection of high NMDA $(30,40)$ and high AMPA $(30,40)$ conductance combinations, $<5 \%$ of stimuli elicited at least three action potentials (data not shown).

Small isolated AMPA conductances were not very effective at firing the cell, but as the AMPA conductance was increased, the percentage of stimuli that elicited a single action potential progressively increased (Fig. $8 D$ ). For even the largest AMPA conductance we tested, individual stimuli were unable to evoke multiple action potentials (Fig. $8 D$ ). The response was drastically altered with the addition of a $40 \mathrm{nS}$ NMDA conductance (Fig. 8E). There were fewer stimuli that failed to evoke an action potential at all conductances. For example, even at 10 $\mathrm{nS},>50 \%$ of stimuli elicited a single action potential. Furthermore, there were many occurrences of multiple spikes per stimulus, particularly at higher AMPA values (Fig. 8E).
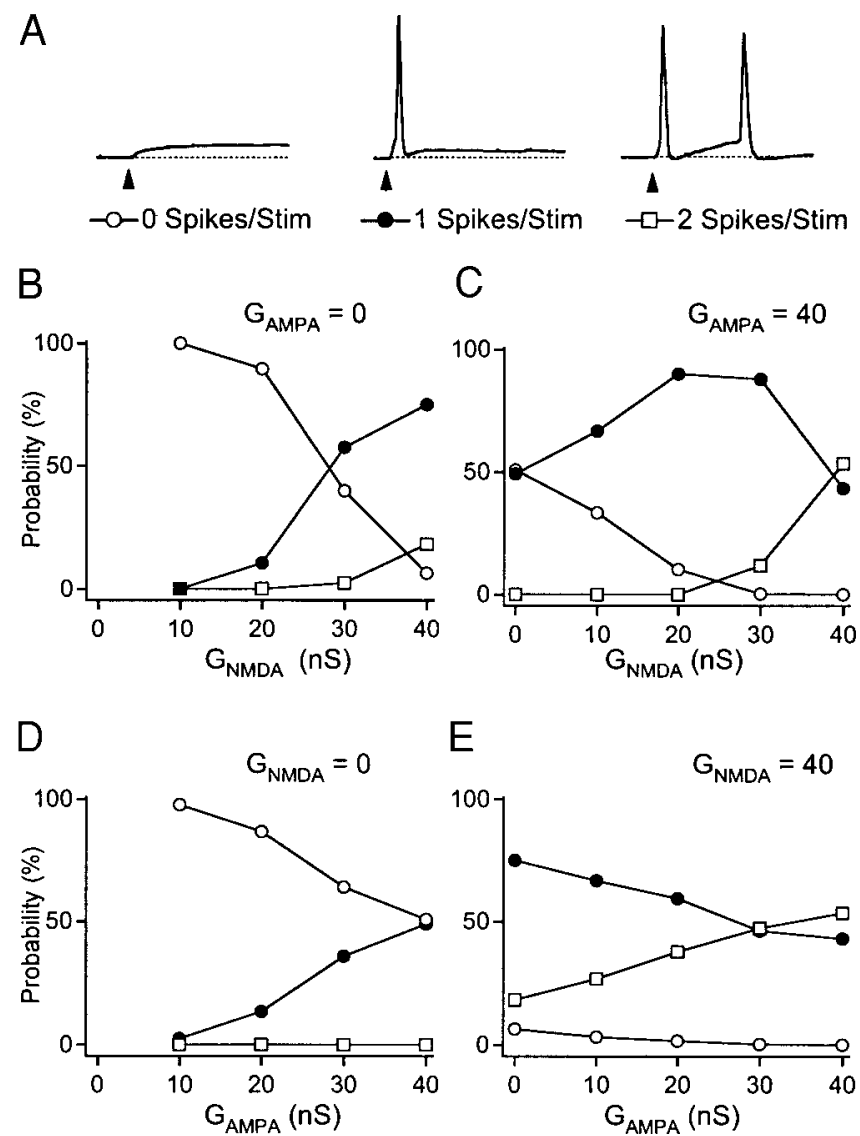

FIG. 8. AMPA and NMDA currents make distinct contributions to the number of action potentials elicited per stimulus. Dynamic-clamp was used to inject varying amounts of AMPA and NMDA conductance, and the number of action potentials elicited by each stimulus within the train was determined. $A$ : example recordings show responses to stimuli that elicited 0,1 , or 2 action potentials. $B-E$ : the average percentage of stimuli that elicited 0,1 , or 2 action potentials is plotted for different conductance combinations ( $n=6$ cells, 4 trials/cell). The NMDA conductance was varied from 0 to $40 \mathrm{nS}$ with either 0 $\mathrm{nS}$ AMPA $(B)$ or $40 \mathrm{nS}$ AMPA $(C)$. The AMPA conductance was varied from 0 to $40 \mathrm{nS}$ with either $0 \mathrm{nS}$ NMDA $(D)$ or $40 \mathrm{nS}$ NMDA $(E)$. Data were re-analyzed from Fig. 7. 
In addition to magnitude of the peak conductances, the timing of activation of AMPA and NMDA currents is likely to play a role in their ability to elicit action potentials. We therefore examined how presynaptic spike timing within the train influenced the ability of AMPA and NMDA currents to elicit one or two action potentials per stimulus. Data from Fig. 8 were re-analyzed to determine the percentage of times each stimulus in the train elicited one or two action potentials (6 cells, 4 trials/cell; Fig. 9). The ability of dynamic-clamp AMPA currents to elicit a single action potential decreased dramatically for stimuli that arrived close together in time (Fig. 9, top). With longer inter-stimulus intervals, the efficacy of individual AMPA EPSPs was much greater. As demonstrated in the preceding text, individual AMPA EPSPs were unable to elicit spike doublets.

The efficacy of NMDA EPSPs had a very different dependence on presynaptic spike timing. Short interstimulus intervals resulted in increased NMDA EPSP efficacy and more spike doublets were elicited (Fig. 9, middle). This is likely due to summation of the long duration NMDA currents. When interstimulus intervals were longer, NMDA EPSPs were much more likely to elicit one than two action potentials.

The distinct properties of the AMPA and NMDA currents acted cooperatively when both AMPA and NMDA dynamicclamp currents were injected. Although a succession of isolated NMDA EPSPs was necessary to elicit spike doublets in $\sim 50 \%$ of the trials (Fig. 9, middle), when AMPA EPSPs were also present, the first stimulus in the train elicited doublets in

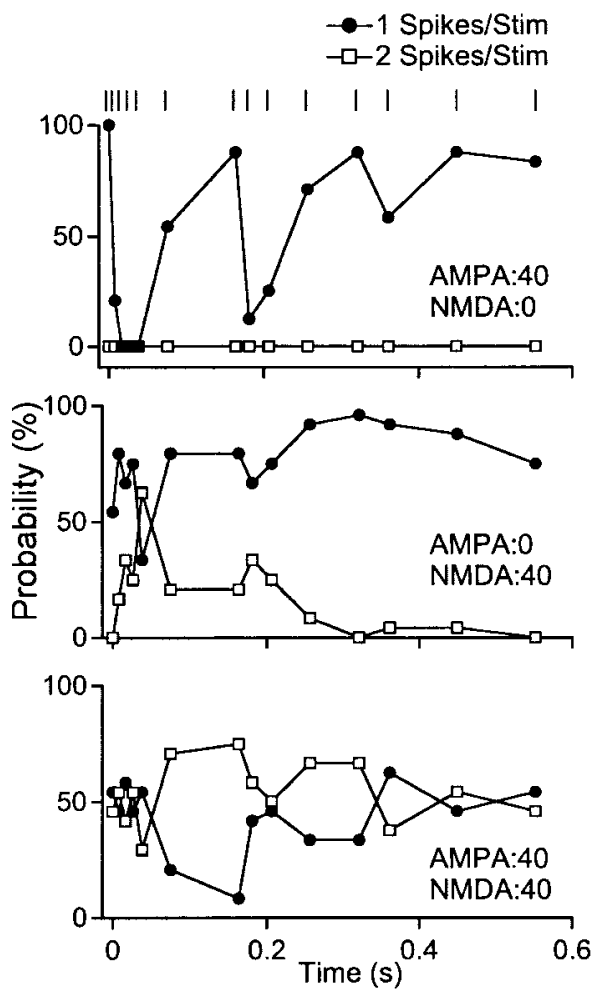

FIG. 9. Contributions of AMPA and NMDA currents to spike number are dependent on presynaptic spike timing. The percentage of trials in which an individual stimulus elicited 1 or 2 action potentials is plotted against the time of occurrence of each stimulus in the train for conductance combinations of 40 AMPA, 0 NMDA (top), 0 AMPA, 40 NMDA (middle), and 40 AMPA, 40 NMDA (bottom). Stimulus pattern is indicated at top by vertical bars; $n=6$ cells, 4 trials/cell. $\sim 50 \%$ of trials. Similarly, NMDA current increased the efficacy of AMPA EPSPs occurring with short inter-stimulus intervals, even later in the train when there is not a great deal of NMDA summation (Fig. 9, bottom).

Thus responses to controlled amplitudes of dynamic-clamp AMPA and NMDA currents demonstrate that AMPA currents can contribute a single, short-latency, precisely timed action potential. However, NMDA currents can contribute longerlatency action potentials with more jitter and can elicit multiple action potentials per stimulus. These properties of AMPA and NMDA are further shaped by the timing of stimuli within a train.

\section{Investigating the variability of responses}

The qualitative and quantitative differences in responses elicited by distinct simulated AMPA and NMDA components suggested different AMPA and NMDA amplitudes might be responsible for the observed variability in synaptically evoked responses. However, given our use of a potassium-based internal solution, we could not quantify the AMPA and NMDA amplitudes in each cell in voltage-clamp mode and correlate differences in amplitudes with differences in current-clamp responses. Instead, to address this, we examined responses to 24 combinations of AMPA and NMDA conductances within individual neurons. We varied AMPA and NMDA conductances from 0 to $40 \mathrm{nS}$, the range we recorded in voltage clamp with a cesium-based internal solution. Three combinations are shown to illustrate our findings (Fig. 10). In a representative neuron at $-55 \mathrm{mV}$, low AMPA and NMDA $(20,10 \mathrm{nS})$ elicited zero to one action potential across the entire train. A spike pattern that closely followed the stimulus train was elicited by high AMPA and low NMDA (40, $10 \mathrm{nS})$. High AMPA, high NMDA $(30,40 \mathrm{nS})$ elicited one to two action potentials per EPSP (Fig. 10A, top).

Although pronounced differences were observed in response to different sizes of conductances, there was less variation in the responses to a single conductance combination. Raster plots demonstrate the consistency of responses within a cell evident by the similarity in each grouping of four consecutive trials (Fig. 10A, bottom). Furthermore, the responses elicited by a conductance combination were similar in multiple cells $(n=$ 6 cells).

We found the same trend at $-75 \mathrm{mV}$. In a single representative neuron, the responses ranged from a single initial burst $(20,10 \mathrm{nS})$ to multiple bursts per train $(40,10$, and $30,40 \mathrm{nS}$; Fig. $10 B$, top). Responses elicited at $-75 \mathrm{mV}$ displayed greater variability across different AMPA/NMDA combinations than across different trials or different cells $(n=5$ cells, 4 trials/ cell; Fig. 10B, bottom). There were no AMPA/NMDA combinations that elicited one-for-one action potentials with the stimulation pattern when relay neurons were at $-75 \mathrm{mV}(n=$ 5 cells, 24 combinations/cell).

Responses elicited with our dynamic clamp simulated inputs mimicked the range of responses elicited by real synaptic inputs at both -55 and $-75 \mathrm{mV}$ (compare Fig. 10, $A$ and $B$, to $2, A$ and $C$ ). These data suggest that variations in AMPA and NMDA amplitudes likely generate the distinct responses of individual relay neurons to RGC inputs. 
A
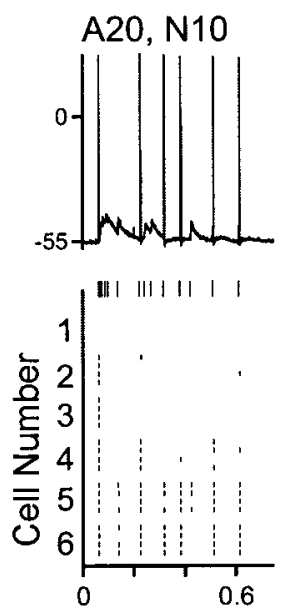

B
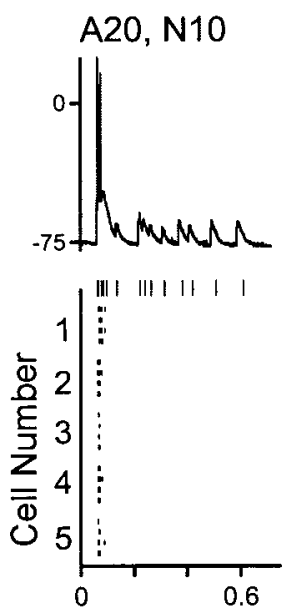

Tonic Mode
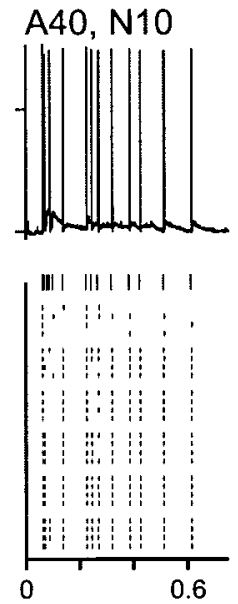

Burst Mode
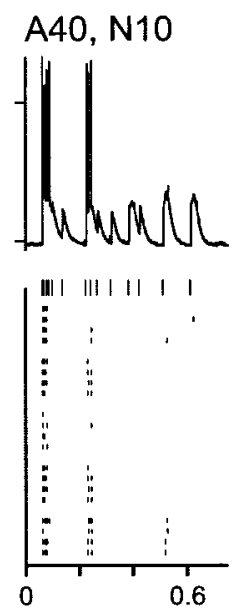

A30, N40
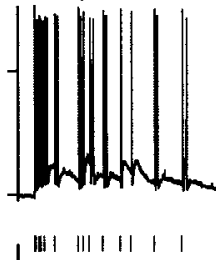

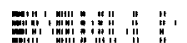

E: : :

\#:

쿠 : : : : : : $:$

政:

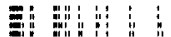

$\stackrel{0.6}{0}$
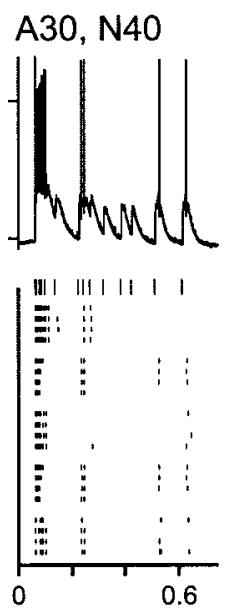

FIG. 10. Dynamic-clamp recordings suggest that variations in the sizes of the AMPA and NMDA components are a major factor in governing the responses of relay neurons to retinogeniculate activation. Dynamic-clamp recordings were used to activate relay neurons with artificial retinogeniculate synaptic inputs with 24 combinations of AMPA and NMDA peak conductances. Results from 3 example combinations are shown here, including AMPA 20:NMDA 10, AMPA 40:NMDA 10, and AMPA 30:NMDA 40. Experiments were performed at $-55 \mathrm{mV}(A)$ and $-75 \mathrm{mV}(B)$. Representative recordings from the same cell show the responses to each combination of conductances at $-55 \mathrm{mV}(A$, top $)$ and $-75 \mathrm{mV}(B$, top $)$. Raster plots demonstrate the evoked spiking activity in response to each combination of artificial synaptic currents during 4 trials/cell in 6 cells at $-55 \mathrm{mV}(A$, bottom) and 5 cells at $-75 \mathrm{mV}(B$, bottom $)$. The single row of vertical bars at the top of graphs represents the stimulus pattern.

\section{I S C U S S I O N}

In this study, we examined synaptic properties controlling how retinal ganglion cell activity is conveyed to LGN relay neurons. AMPA and NMDA components contribute in different ways to transmission. In tonic mode, the AMPA component evokes precisely timed short-latency action potentials, whereas the NMDA component triggers additional action potentials with longer latencies and more variable timing. Synaptic properties contribute to the strength of responses in burst mode, but timing information about the stimulus is lost. We found that short-term synaptic plasticity decreases the efficacy of the AMPA component, whereas without plasticity, AMPA current alone would very effectively fire relay neurons even during

high-frequency trains. A consequence of this plasticity, in combination with the time course of the synaptic currents, is that the pattern of presynaptic spikes influences their efficacy. We found that a given RGC input evokes stereotyped responses from a relay neuron but that the same pattern of activity in different RGC inputs evokes a broad range of responses in different relay neurons. Dynamic-clamp experiments suggest that much of the variability between different cells reflects differences in the magnitude of AMPA and NMDA components.

\section{Responses to single RGC inputs}

We found that activation of individual RGC inputs to relay cells with a physiological spike train elicited firing in relay neurons that depended on a number of factors. In burst mode, synaptic activation triggered low-threshold calcium spikes that in turn produced high-frequency bursts of sodium spikes. Consequently, precise timing information is not preserved in burst mode. The inability to follow the stimulus pattern and the strong initial response are consistent with the hypothesis that relay neurons in burst mode may be better suited to signal the presence of novel stimuli than to relay detailed visual information (Guido and Weyand 1995; Sherman 2001a,b; Swadlow and Gusev 2001). In contrast, in tonic mode, single RGC inputs evoked responses that reliably followed the stimulation pattern. This underscores the ability of relay neurons in tonic mode to convey timing information reliably to the cortex as has been observed in vivo (Guido et al. 1995; Mukherjee and Kaplan 1995; Sherman 1996). We found that in both tonic and burst mode, the number of spikes elicited by RGC activity is influenced by the sizes of the NMDA and AMPA components and use-dependent synaptic plasticity.

\section{Distinct roles of AMPA and NMDA receptors in tonic mode}

In tonic mode, the AMPA and NMDA components make distinct contributions to relay neuron responses. AMPA receptors are well suited for eliciting precise short-latency firing that preserves timing information. However, the influence of the AMPA component is limited by its short duration and the significant receptor desensitization. Longer-latency responses were blocked by CPP and elicited with simulated NMDA conductance demonstrating the importance of NMDA current for this aspect of relay neuron responses.

There are several reasons why retinogeniculate synapses may use both NMDA and AMPA components to influence relay neurons. The AMPA component is best suited to firing the cell with high precision in keeping with a number of in vivo experiments that highlight the preservation of timing information at this synapse (Liu et al. 2001; Reinagel and Reid 2000, 2002). The NMDA component, however, contributes to eliciting spikes with longer latencies and more variability in their timing. Similarly, in cortical neurons, addition of simulated NMDA conductance increases timing variability (Harsch and Robinson 2000). Furthermore, when the NMDA component is prominent, a single spike in a retinal ganglion cell can trigger multiple spikes in a relay neuron even when the relay cell is in tonic mode. The additional depolarization from the NMDA current might also activate intrinsic currents that could amplify the RGC input. This suggests that a relay cell need not be in 
burst mode to amplify RGC input provided the retinogeniculate synapse has a prominent NMDA component. The additional action potentials elicited by NMDA current are likely to be important in the efficacy of relay neuron synapses onto cortical neurons. Usrey et al. (2000) demonstrated that the second of two LGN relay neuron action potentials occurring within $15 \mathrm{~ms}$ of each other is more likely to elicit a spike in a postsynaptic cortical cell. Furthermore, in somatosensory cortex, thalamic bursts are very effective at eliciting spikes in cortical neurons (Swadlow and Gusev 2001). Therefore AMPA and NMDA make distinct contributions on the millisecond time scale to both the precision and the strength of relay neuron responses. Because these two conductances regulate different aspects of the relay neuron response, it is possible that differential modulation of the NMDA and AMPA components could independently regulate the efficacy of short- and long-latency responses.

Under normal physiological conditions, both AMPA and NMDA components are present and can work together to mediate visual responses. The depolarization produced by AMPA receptors helps to relieve the voltage-dependent block of NMDA receptors. In this way, even during high-frequency repetitive activity when AMPA currents are highly depressed, AMPA receptors help NMDA receptors trigger postsynaptic spikes. In addition, the NMDA component can lead to longlasting depolarizations that keep the relay cell near threshold. Therefore the NMDA component enables subsequent AMPA currents to be more effective. Thus interactions between these two components are also important for how ganglion cell inputs control relay neuron firing.

\section{Contributions of activity-dependent synaptic plasticity in tonic mode}

We found that activity-dependent plasticity at the retinogeniculate synapse is an important factor in shaping relay neuron responses. Presynaptic depression and postsynaptic AMPA receptor desensitization are both prominent at this synapse (Chen et al. 2002). Our dynamic-clamp experiments demonstrate that without this plasticity, the AMPA component would be able to drive the relay neuron reliably and precisely throughout the train. However, depression and desensitization limit the efficacy of the synapse during the train and make the efficacy sensitive to the timing of the ganglion cell action potentials. As a result, the AMPA receptor elicited relay neuron response is much stronger after a prolonged pause in the firing of the retinal input, whereas during high-frequency sustained activation, it is weakened significantly. These mechanisms of synaptic plasticity enable the retinogeniculate synapse to transform the firing patterns of the inputs it receives and alter the visual information conveyed to the cortex. Despite receptor saturation (Chen et al. 2002), the NMDA component makes more prominent contributions during periods of high-frequency activity due to the slow kinetics of these currents. In this way, it can complement the AMPA component, which is particularly ineffective during such patterns of activity.

It is likely that the contributions of the NMDA and AMPA components and synaptic plasticity to retinogeniculate activation of relay neurons depend on the activity pattern of RGCs. Here we have used relatively short-duration trains separated by long quiescent periods in the absence of inhibition. It is there- fore not surprising that the dependence of RGC efficacy on spike timing measured here differs from that observed in vivo in response to visual stimulation that gives rise to more prolonged RGC activity without such long quiescent periods. In such experiments, the second of two closely spaced spikes is more effective at evoking a response in relay neurons (Levine and Cleland 2001; Mastronarde 1987; Rowe and Fischer 2001; Usrey et al. 1998). Further experiments using stimulus trains that better correspond to RGC activity during such in vivo experiments will be required to determine how synaptic properties contribute to the dependence of efficacy on presynaptic spike timing measured in vivo. In addition to synaptic properties, intrinsic relay neuron properties are also likely to be altered by background levels of RGC input. Therefore it will be useful to determine how synaptic and cellular properties interact to shape retinogeniculate efficacy during RGC activity patterns that occur on a background of synaptic input.

\section{Reproducibility of responses}

We found that activation of a single RGC input with a physiological pattern of activity evoked remarkably stereotyped responses in repeated trials. These reproducible responses are consistent with retinogeniculate synapses transforming input from ganglion cells in a stereotyped way before transmitting the resulting spikes to cortical synapses (Kara et al. 2000; Liu et al. 2001; Reinagel and Reid 2000, 2002). Although all responses at $-55 \mathrm{mV}$ were closely related to the stimulus pattern, there were cell-to-cell differences in the spiking patterns evoked by activation of synaptic inputs. Our dynamic-clamp experiments show that the same size NMDA and AMPA components evoke similar patterns of activity in different cells. These results are reminiscent of the similarity in responses of different relay neurons evoked by repeated presentations of the same visual stimulus (Reinagel and Reid 2002). Our results suggest that modulation of intrinsic properties primarily determines whether relay neurons are in burst or tonic mode, whereas the distinct responses between cells within a mode are likely to arise from modulation of the amplitudes and balance of the two synaptic currents.

\section{Summary}

This study allowed us to answer a number of questions regarding transmission at the retinogeniculate synapse. First, we found that depression and desensitization of the AMPA component contribute to the inability of RGCs to reliably trigger relay neuron firing despite the initial strength of this connection. Second, the AMPA component preserves timing information about the stimulus with precise short-latency action potentials, while the NMDA component can produce amplification and elicit long-latency spikes. Third, these synapses are suited to triggering highly reproducible and stereotyped relay neuron responses that depend on the sizes of the NMDA and AMPA components. Fourth, use-dependent synaptic plasticity makes the efficacy of RGC spikes highly sensitive to presynaptic spike timing. Finally, RGC inputs elicit burst firing either in burst mode, or in tonic mode with a sufficient NMDA component. Thus the characteristics of AMPA and NMDA currents, use-dependent synaptic plasticity and the mode of the relay neuron, interact to influence how RGC activity is conveyed to relay neurons. 
We thank M. Beierlein, S. Brenowitz, S. Brown, K. Foster, P. Kara, P. Safo, and $\mathrm{M}$. Xu-Friedman for helpful suggestions on this manuscript. We thank A Carter for help with the dynamic-clamp technique.

\section{I S C L O S URES}

This work was supported by National Institute of Neurological Disorders and Stroke Grant PO1-NS-38312.

\section{REFERENCES}

Bloomfield SA, Hamos JE, and Sherman SM. Passive cable properties and morphological correlates of neurons in the lateral geniculate nucleus of the cat. J Physiol 383: 653-692, 1987.

Chen C, Blitz DM, and Regehr WG. Contributions of receptor desensitization and saturation to plasticity at the retinogeniculate synapse. Neuron 33: 779-788, 2002.

Chen C and Regehr WG. Developmental remodeling of the retinogeniculate synapse. Neuron 28: 955-966, 2000.

Cleland BG and Lee BB. A comparison of visual responses of cat lateral geniculate nucleus neurons with those of ganglion cells afferent to them. J Physiol 369: 249-268, 1985.

Crunelli V, Leresche N, and Parnavelas JG. Membrane properties of morphologically identified $\mathrm{X}$ and $\mathrm{Y}$ cells in the lateral geniculate nucleus of the cat in vitro. J Physiol 390: 243-256, 1987.

Crunelli V, Lightowler S, and Pollard CE. A T-type $\mathrm{Ca}^{2+}$ current underlies low-threshold $\mathrm{Ca}^{2+}$ potentials in cells of the cat and rat lateral geniculate nucleus. J Physiol 413: 543-561, 1989.

Esguerra M, Kwon YH, and Sur M. Retinogeniculate EPSPs recorded intracellularly in the ferret lateral geniculate nucleus in vitro: role of NMDA receptors. Vis Neurosci 8: 545-555, 1992.

Guido W, Lu SM, Vaughan JW, Godwin DW, and Sherman SM. Receiver operating characteristic (ROC) analysis of neurons in the cat's lateral geniculate nucleus during tonic and burst response mode. Vis Neurosci 12: 723-741, 1995.

Guido W and Weyand T. Burst responses in thalamic relay cells of the awake behaving cat. J Neurophysiol 74: 1782-1786, 1995.

Hamos JE, Van Horn SC, Raczkowski D, and Sherman SM. Synaptic circuits involving an individual retinogeniculate axon in the cat. J Comp Neurol 259: 165-192, 1987.

Harsch A and Robinson HPC. Postsynaptic variability of firing in rat cortical neurons: the roles of input synchronization and synaptic NMDA receptor conductance. J Neurosci 20: 6181-6192, 2000.

Hartveit $\mathbf{E}$ and Heggelund P. Neurotransmitter receptors mediating excitatory input to cells in the cat lateral geniculate nucleus. II. Nonlagged cells. J Neurophysiol 63: 1361-1372, 1990.

Jahnsen $\mathbf{H}$ and Llinas R. Electrophysiological properties of guinea-pig thalamic neurons: and in vitro study. J Physiol 349: 205-226, 1984a.

Jahnsen $\mathbf{H}$ and Llinas R. Ionic basis for the electroresponsiveness and oscillatory properties of guinea pig thalamic neurons in vitro. J Physiol 349: 227-247, 1984b.

Kara P, Reinagel P, and Reid RC. Low response variability in simultaneously recorded retinal, thalamic, and cortical neurons. Neuron 27: 635646, 2000

Kwon YH, Esguerra M, and Sur M. NMDA and non-NMDA receptors mediate visual responses of neurons in the cat's lateral geniculate nucleus. J Neurophysiol 66: 414-428, 1991.

Levine MW and Cleland BG. An analysis of the effect of retinal ganglion cel impulses upon the firing probability of neurons in the dorsal lateral geniculate nucleus of the cat. Brain Res 902: 244-254, 2001.
Liu RC, Tzonev S, Rebrik S, and Miller KD. Variability and information in a neural code of the cat lateral geniculate nucleus. J Neurophysiol 86: 2789-2806, 2001.

Mastronarde DN. Two classes of single-input X cells in cat lateral geniculate nucleus. II. Retinal inputs and the generation of receptive-field properties. J Neurophysiol 57: 381-413, 1987.

Mayer ML and Westbrook GL. Permeation and block of $N$-methyl-Daspartic acid receptor channels by divalent cations in mouse cultured central neurones. J Physiol 394: 501-527, 1987.

McCormick DA. Neurotransmitter actions in the thalamus and cerebral cortex and their role in neuromodulation of thalamocortical activity. Prog Neurobiol 39: 337-388, 1992.

Mukherjee P and Kaplan E. Dynamics of neurons in the cat lateral geniculate nucleus: in vivo electrophysiology and computational modeling. J Neurophysiol 74: 1222-1243, 1995.

Ramcharan EJ, Gnadt JW, and Sherman SM. Burst and tonic firing in thalamic cells of unanesthetized, behaving monkeys. Vis Neurosci 17: 55-62, 2000.

Reinagel $\mathbf{P}$ and Reid RC. Temporal coding of visual information in the thalamus. J Neurosci 20: 5392-5400, 2000.

Reinagel P and Reid RC. Precise firing events are conserved across neurons. J Neurosci 22: 6837-6841, 2002.

Rowe MH and Fischer Q. Dynamic properties of retino-geniculate synapses in the cat. Vis Neurosci 18: 219-231, 2001.

Scharfman HE, Lu SM, Guido W, Adams PR, and Sherman SM. $N$ methyl-D-aspartate receptors contribute to excitatory postsynaptic potentials of cat lateral geniculate neurons recorded in thalamic slices. Proc Natl Acad Sci USA 87: 4548-4552, 1990

Sherman SM. Dual response modes in lateral geniculate neurons: mechanisms and functions. Vis Neurosci 13: 205-213, 1996.

Sherman SM. A wake-up call from the thalamus. Nat Neurosci 4: 344-346, 2001a.

Sherman SM. Tonic and burst firing: dual modes of thalamocortical relay. Trends Neurosci 24: 122-126, $2001 \mathrm{~b}$.

Sherman SM and Guillery RW. Functional organization of thalamocortical relays. J Neurophysiol 76: 1367-1395, 1996.

Sillito AM, Murphy PC, Salt TE, and Moody CI. Dependence of retinogeniculate transmission in cat on NMDA receptors. J Neurophysiol 63: 347-355, 1990.

Soltesz I and Crunelli V. GABAA and pre- and post-synaptic GABAB receptor-mediated responses in the lateral geniculate nucleus. Prog Brain Res 90: 151-169, 1992.

Steriade M, Jones EG, and McCormick DA. Thalamus. Oxford, UK: Elsevier Science, 1997.

Swadlow HA and Gusev AG. The impact of "bursting" thalamic impulses at a neocortical synapse. Nat Neurosci 4: 402-408, 2001.

Turner JP, Leresche N, Guyon A, Soltesz I, and Crunelli V. Sensory input and burst firing output of rat and cat thalamocortical cells: the role of NMDA and non-NMDA receptors. J Physiol 480: 281-295, 1994.

Usrey WM. Spike timing and visual processing in the retinogeniculocortical pathway. Philos Trans R Soc Lond B Biol Sci 357: 1729-1737, 2002.

Usrey WM, Alonso JM, and Reid RC. Synaptic interactions between thalamic inputs to simple cells in cat visual cortex. J Neurosci 20: 5461-5467, 2000.

Usrey WM, Reppas JB, and Reid RC. Paired-spike interactions and synaptic efficacy of retinal inputs to the thalamus. Nature 395: 384-387, 1998.

Usrey WM, Reppas JB, and Reid RC. Specificity and strength of retinogeniculate connections. J Neurophysiol 82: 3527-3540, 1999.

Weyand TG, Boudreaux M, and Guido W. Burst and tonic response modes in thalamic neurons during sleep and wakefulness. J Neurophysiol 85: 1107-1118, 2001. 